\title{
Effect of lutein on lipid profile in hypercholesterolemic rats
}

\author{
Uma Narayanamurthy ${ }^{1 *}$, Anandhi M. $^{2}$, Manimekalai K. ${ }^{1}$
}

${ }^{1}$ Department of Pharmacology, ${ }^{2}$ MBBS Student, Mahatma Gandhi Medical College \& Research Institute, SBV Universtiy, Pillaiyarkuppam, Puducherry 607402, India

Received: 21 January 2018 Accepted: 05 March 2018

*Correspondence to:

Dr. Uma Narayanamurthy, Email: numa.lally@gmail.com

Copyright: (C) the author(s), publisher and licensee Medip Academy. This is an openaccess article distributed under the terms of the Creative Commons Attribution NonCommercial License, which permits unrestricted noncommercial use, distribution, and reproduction in any medium, provided the original work is properly cited.

\begin{abstract}
Background: Hyperlipidemia or Dyslipidemia is the major cause of atherosclerosis1 and associated conditions. Low levels of high-densitylipoprotein cholesterol (HDL-C) are the major causes of increased atherogenic risk 1. Aggressive cholesterol reduction in patients with atherosclerotic disease is now the standard of care2. In addition to life style modification, patients with risk factors need lipid lowering drug therapy. The drugs available now do not reduce LDL oxidation, and oxidative stress associated with hyperlipidemia. In recent years, antioxidants have been subjected to epidemiological studies4 that have related their consumption to a reduction in the incidence of oxidative damage related diseases.
\end{abstract}

Methods: Hypercholesterolemia was induced in rats by administration of high cholesterol diet for 30 days in standard rat chow diet. Rats were divided into four groups of six each. Group-I and II with intake of normal diet and High cholesterol diet respectively. Group III and IV are given high cholesterol diet along with Lutein $50 \mathrm{mg} / \mathrm{kg}$ and Atorvastatin $5 \mathrm{mg} / \mathrm{kg}$ orally once daily respectively. At the end of 30 days animals were subjected to overnight fasting. Blood samples were drawn by retro-orbital puncture for biochemical analysis. The animals were sacrificed after thiopentone injection and liver and aorta were dissected out and processed for histopathological study and biochemical analysis.

Results: Lutein treated group showed even more significant reduction in TBARS levels than the normal control group and Atorvastatin treated group. The efficacy of Lutein in slowing down the atherosclerosis and fatty infiltration of liver is proved in this study.

Conclusions: Hence the present study had shown significant hypolipidemic, antiatherogenic and antioxidant effect of Luetin in Hyperlipidemic rats.

Keywords: Aorta, Hyperlipidemia, Liver, Lutein, Oxidative stress

\section{INTRODUCTION}

Hyperlipidemia or Dyslipidemia is the major cause of atherosclerosis and atherosclerosis associated conditions, such as coronary heart disease (CHD), ischaemic cerebrovascular disease and peripheral vascular disease. Atherosclerotic CHD is a worldwide disease. ${ }^{1}$

Hypercholesterolemia and low levels of high-densitylipoprotein cholesterol (HDL-C) are the major causes of increased atherogenic risk. ${ }^{1}$ As opposed to the atherogenic potential of IDL and LDL, HDL particles are protective against atherosclerotic plaque formation. High HDL-C levels are associated with lower incidence of CHD. Both genetic factors and lifestyle contribute to the dyslipidemia seen in countries around the world.

An integrated view of experimental results in animals and study of human atherosclerosis suggest that Low density lipoproteins accumulate in the intima of arteries, undergo oxidative modifications, and form foam cells, which are 
the key constituents of fatty streaks and the earliest phase of atherosclerotic plaque.

Aggressive cholesterol reduction in patients with CHD or other atherosclerotic disease is now the standard of care. ${ }^{2}$ Primary prevention of CHD is extremely important as approximately one quarter to one third of initial myocardial infarction result in death, preventing the opportunity of secondary prevention. ${ }^{3}$

Dyslipidemia has a vulnerable history which had left evidence in arteries of Egyptian Mummies. The ill effects of this condition were well studied and documented by the ancient sages of India. The "Dhatwagni" or the tissue fire (enzyme systems) concerned with the fat metabolism was the main culprit in this. As a result of deranged fat metabolism even diseases of a life-threatening nature were liable to occur. Charaka (600 B.C) had described this in his samhita in the twenty first chapter of Soothrasthana. The abnormal increase of the fat can vitiate all the three doshas (humour) in the body and in extreme cases it could even cause death.

The etiological factors of this condition had been grouped under four heads- They were 'Beeja-Swabhava' (Genetic predisposition) 'Avyayama' (lack of physical exercise) 'Divaswapa' (sleeping during day time for long) and 'guru Madhura seethe- snigdhopayoga'. (excessive usage of heavy, sweet, cold and fatty diet). Pathological changes occurring were 'Margarodha' or obstruction in blood vessels, 'Dhamaniprathichaya' or thickening of blood vessels 'Medo Vridhasayas' or fatty infiltration of organs and abnormal functioning of the 'Sweda grandhis' or sweat glands. The main diseases arising from this derangement were 'Vidradhi' (boils) 'galagandam' (goiter) 'Grandhi' (Tumours) 'Madhumeha' (Diabetes mellitus) 'Apachi' (a type of chronic lymph). ${ }^{4}$ From this all new look on the ancient histories the travel was towards the invention of drugs for treatment of dyslipidemia that was when in 1978, Alfred Albert and colleagues at Merck Research Laboratories discovered a new natural product in a fermentation broth of Aspergillus terreus, their product showed good HMG CoA reductase inhibition and they named the product mevinolin, which was later known as lovastatin, and from that time onwards many drugs were being discovered and marketed. ${ }^{5}$

In addition to life style modification, patients with risk factors (Diabetes mellitus, Hypertension, Low HDL, Family history of CHD and LDL $\geq 130 \mathrm{mg} / \mathrm{dl}$ ) need lipid lowering drug therapy. The drugs available now do not reduce LDL oxidation, and oxidative stress associated with hyperlipidemia. In recent years, antioxidants have been subjected to epidemiological studies that have related their consumption to a reduction in the incidence of oxidative damage related diseases like ageing, cardiovascular diseases, diabetes, inflammation and neurodegenerative disorders. ${ }^{6}$ Many antioxidants such as tocotrieenol, Lutein, vitamin $\mathrm{C}$, have been reported to protect against induced hypercholesterolemia. ${ }^{7-9}$ These antioxidants reduce LDL oxidation and preserve vasoreactivity.

Lutein is one of the hundreds of known naturally oxygenated carotenoids and has potential antioxidant properties. Some epidemiological studies found that serum HDL-C was positively associated, and oxidized LDL was negatively associated with serum Lutein levels. ${ }^{5}$ Hence the present study had shown significant hypolipidemic and antiatherogenic effect of Luetin in rats fed on hypercholesterolemic diet.

Unhealthy dietary practices and genetic factors contribute to the development of dyslipidemia which the major cause of atherosclerosis and it is induces conditions like coronary heart disease and ischaemic cerebrovascular disease. Atherogenesis is initiated by LDL-C oxidation. As a corollary to this hypothesis, antioxidant that inhibits lipid peroxidation should limit atherosclerosis and its clinical manifestations.

\section{METHODS}

The study was undertaken at Central Animal House, Mahatma Gandhi Medical College and Research Centre, SBV University, Puducherry, India. All studies were conducted in accordance with the National Institute of Health "Guide for the care and use of Laboratory Animals" (NIH, 1985). The study was approved by the Institutional Animal Ethics Committee, Mahatma Gandhi Medical College and Research Institute (Registration no: 686/PO/Re/S/02/CPCSEA) SBV University, Puducherry, India (Proposal 02/IAEC/MG/01, April 2016).

\section{Materials}

\section{Chemicals and reagents}

- Lutein 50mg tablets was obtained through Amazon.in from Herbal formulations pvt. ltd.

- Atorvastatin 5mg tablets was obtained from Pharmacy, MGMCRI, Puducherry.

- Cholesterol and sodium cholate in powder form were obtained from Hi Media chemicals.

\begin{abstract}
Animals
Male Wistar rats of 150-200 gms were used for this study. They were housed in groups of six under controlled environmental conditions (Temp- $23 \pm 2^{\circ} \mathrm{C}$, Humidity 65$70 \%$ and $12 \mathrm{hrs}$ light/dark cycles) at Central Animal House, Mahatma Gandhi Medical College, SBV University, Pillaiyarkuppam, Puducherry, India. Animals were fed with standard pellet diet and water ad libitum.
\end{abstract}

\section{Experimental induction of hypercholesterolemia}

Hypercholesterolemia was induced in rats by administration of High Cholesterol Diet (1\% cholesterol, 
$0.5 \%$ sodium cholate, $1 \%$ coconut oil) for 30 days in standard rat chow diet.

\section{Study design}

The Rats were divided into four groups of six each. The animals were housed in the animal house for 60 days.

- Group-I $(n=6)$ Normal control. Treated with normal diet only.

- Group-II $(\mathrm{n}=6)$ Experimental control. High cholesterol diet

- Group-III (n=6) High cholesterol diet + Lutein $50 \mathrm{mg} / \mathrm{kg} 10$ orally once daily

- Group-IV (n=6) High cholesterol diet + Atorvastatin $5 \mathrm{mg} / \mathrm{kg}$ orally once daily. ${ }^{10}$

The animals in all the groups were fed with standard pellet diet and water ad libitum during the experimental period. Lutein was mixed with normal saline and administered through oral intragastric tube to groups III and Atorvastatin was mixed with dimethyl sulfoxide (DMSO) and administered through oral intragastric tube to group IV.

\section{Blood sampling}

At the end of 30 days after Lutein and Atorvastatin administration the animals in all the groups were subjected to overnight fasting. Blood samples were drawn by retroorbital puncture under intramuscular ketamine for biochemical analysis. The animals were sacrificed after thiopentone injection and liver and aorta were dissected out and processed for histopathological study and biochemical analysis.

\section{Biochemical analysis}

\section{Serum preparation}

The whole blood from rats of each group was collected in covered test tubes. After collection of the whole blood, it was allowed to clot undisturbed for 15-30 minutes. The clot was removed by centrifuging at 1,000-2,000 X $\mathrm{g}$ for 10 minutes in a centrifuge. The supernatant serum was obtained.

\section{Tissue sampling}

The animals were sacrificed after injecting Thiopentone sodium and the liver and aortic tissue from all the groups of rats were dissected out. They were processed for histopathological examination (HPE) and biochemical analysis.

\section{Light microscopic study}

For histopathological study the rat tissues were perfused with $10 \%$ formalin. The Liver and Aortic tissue of the rats were excised immediately from the abdominal cavity and fixed in $10 \%$ neutral formalin, dehydrated in graded alcohol (80\%-100\%), cleaned in xylene and embedded in paraffin. Then hepatic and aortic tissues were sliced into $3-5 \mu \mathrm{m}$ pieces with a rotary microtone, deparaffinised in xylene, passed through varying grades of alcohol and finally stained with haematoxylin and eosin for histopathological assessment. The specimens were evaluated with light microscope. All histopathological changes were examined by pathologist.

\section{Biochemical analysis}

\section{Methods of estimation of lipid profile}

Total cholesterol was estimated by the method of Parekh and Jung. ${ }^{11}$ Total cholesterol values were expressed as $\mathrm{mg} / \mathrm{dl}$ for plasma. Triglycerides were estimated by the method of Foster and Dunn. ${ }^{12}$ The amount of triglycerides was expressed as $\mathrm{mg} / \mathrm{dl}$ for plasma. The HDL cholesterol was estimated by the heparin-manganese chloride precipitation method. ${ }^{13}$ Estimation of VLDL Cholesterol using the formula $\left(\frac{T G}{5}\right)$. The values were expressed as $\mathrm{mg} / \mathrm{dl}$ for plasma. Estimation of LDL Cholesterol using the formula LDL - Cholesterol $=$ Total cholesterol $-\mathrm{HDL}+$ $\left(\frac{T G}{5}\right)$. The values were expressed as $\mathrm{mg} / \mathrm{dl}$ for plasma

\section{Estimation of Thiobarbituric acid reactive substances (TBARS)}

Lipid peroxidation was estimated as evidenced by the formation of thiobarbituric acid reactive substances (TBARS). Lipid peroxides were assayed by the method of Yagi. ${ }^{14}$ Lipid peroxides levels are expressed as $\mu \mathrm{g} / \mathrm{g}$ of the tissue.

\section{Statistical analysis}

Values of Biochemical analyses would be expressed as means \pm SD for six rats in each group. The data would be analyzed by Duncan's multi range test. A value of $\mathrm{p} \leq 0.05$ would be used as the criterion for statistical significance. SPSS $16^{\text {th }}$ version computer software will be used for statistical analysis.

\section{RESULTS}

\section{Effect of lutein on serum lipid profile}

From Table 1 it was observed that high cholesterol diet produced significant increase in $(\mathrm{P}<0.05)$ Total cholesterol, Triglycerides, VLDL-C, and LDL-C. High cholesterol diet also reduced HDL-Cholesterol significantly $(\mathrm{P}<0.05)$. Treatment with Lutein $(50 \mathrm{mg} / \mathrm{kg})$ resulted in significant decrease of Total cholesterol $(20 \%)$, Triglycerides (23\%), VLDL-C (26\%), and LDL-C (18\%) 
and increase of HDL-C (3\%). The effect of Lutein $(50 \mathrm{mg} / \mathrm{kg})$ on high cholesterol diet fed group was almost the same as that of Atorvastatin $(5 \mathrm{mg} / \mathrm{kg})$.

Table 1: Effect of lutein on lipid profile in hypercholesterolemic rats.

\begin{tabular}{|ll|llll|}
\hline Lipid profile & $\begin{array}{l}\text { Total cholesterol } \\
(\mathbf{m g} / \mathbf{d l})\end{array}$ & $\begin{array}{l}\text { Triglycerides } \\
(\mathbf{m g} / \mathbf{d l})\end{array}$ & LDL (mg/dl) & VLDL (mg/dl) & HDL (mg/dl) \\
\hline Group 1 & $48.17 \pm 1.83^{\mathrm{a}}$ & $41.33 \pm 5.57^{\mathrm{a}}$ & $18.17 \pm 1.94^{\mathrm{a}}$ & $8.17 \pm 1.47^{\mathrm{a}}$ & $27.67 \pm 2.58^{\mathrm{a}}$ \\
\hline Group 2 & $109.50 \pm 6.38^{\mathrm{d}}$ & $80.00 \pm 11.95^{\mathrm{c}}$ & $61.50 \pm 3.56^{\mathrm{d}}$ & $15.17 \pm 1.72^{\mathrm{c}}$ & $23.17 \pm 2.78^{\mathrm{d}}$ \\
\hline Group 3 & $82.50 \pm 2.95^{\mathrm{c}}$ & $57.33 \pm 4.41^{\mathrm{b}}$ & $47.00 \pm 4.33^{\mathrm{c}}$ & $10.83 \pm 1.47^{\mathrm{b}}$ & $25.50 \pm 1.51^{\mathrm{c}}$ \\
\hline Group 4 & $79.83 \pm 4.95^{\mathrm{b}}$ & $56.67 \pm 4.96^{\mathrm{b}}$ & $42.50 \pm 2.34^{\mathrm{b}}$ & $10.83 \pm 0.96^{\mathrm{b}}$ & $26.17 \pm 2.78^{\mathrm{b}}$ \\
\hline
\end{tabular}

Values are expressed as means \pm SD for eight Rats in each group.

Values not sharing a common superscript differ significantly at $\mathrm{p} \leq 0.05$

(Dunken's test)

\section{Effect of lutein on plasma lipid peroxides and antioxidant levels}

From Table 2 it was observed that the level of TBARS was significantly increased in high cholesterol diet fed rats $(\mathrm{P}<0.05)$. Lutein $(50 \mathrm{mg} / \mathrm{kg})$ reduced the tissue TBARS significantly $(\mathrm{P}<0.05)$. Lutein treated group showed even more significant reduction in TBARS levels than the normal control group.

Table 2: Effect of lutein on TBARS levels in hypercholesterolemic rats.

\begin{tabular}{|ll|}
\hline Groups & TBARS $(\boldsymbol{\mu g} / \mathrm{g})$ \\
\hline Group 1 & $1768.67 \pm 93.75^{\mathrm{b}}$ \\
\hline Group 2 & $2051.33 \pm 28.33^{\mathrm{c}}$ \\
\hline Group 3 & $1593.00 \pm 81.08^{\mathrm{a}}$ \\
\hline Group 4 & $1596.00 \pm 28.81^{\mathrm{a}}$ \\
\hline
\end{tabular}

\section{Histopathological study of hepatic and aortic tissue}

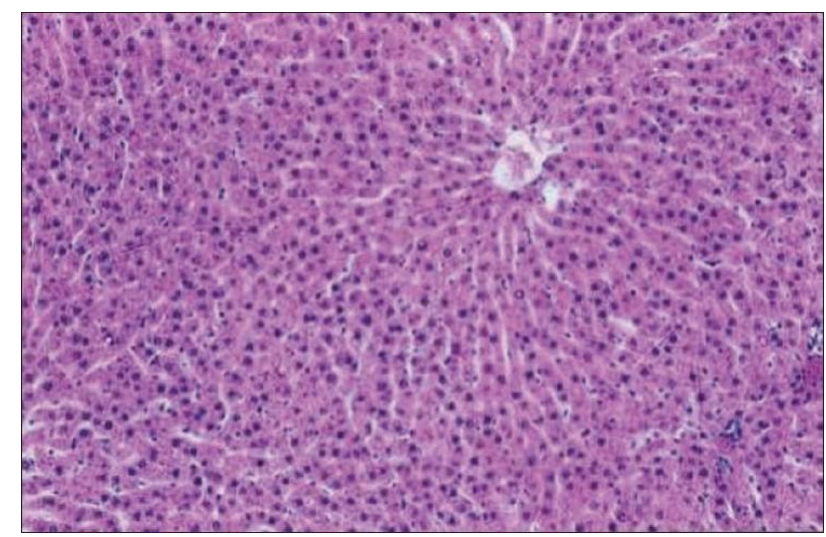

Figure 1: Liver tissue of normal rat showing normal hepatocytes.

In the histopathological study Liver tissue of normal diet fed rats from Group I showed normal hepatocytes without any fat deposits (Figure 1) and Aortic tissue of normal rat with few macrophage derived foam cells seen in the intima of aorta (Figure 5) high cholesterol fed rats showed fatty degeneration of hepatocytes with leucocytic infiltration of sinusoids (Figure 2).

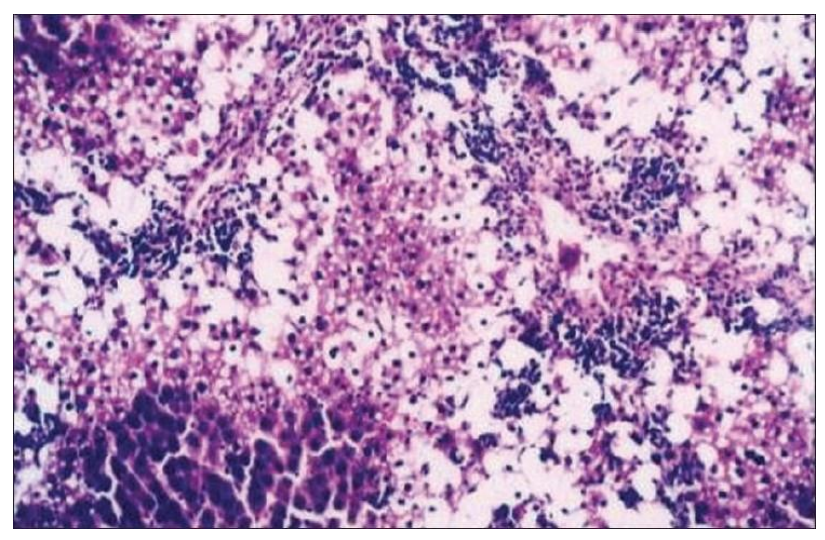

Figure 2: Liver tissue of high cholesterol diet fed rat showing severe fatty degeneration of hepatocytes and infiltration of leucocytes in hepatic sinusoids and abundant macrovesicular and microvesicular droplets of fat within the hepatocytes.

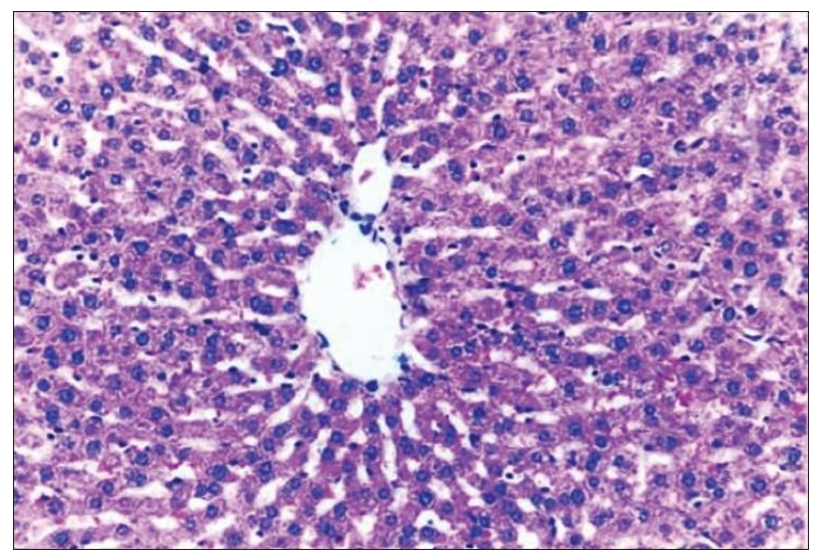

Figure 3: Liver tissue of high cholesterol diet fed rats treated with Lutein $(50 \mathrm{mg} / \mathrm{kg})$ showing mild fatty degeneration of hepatocytes with microvesicular and few macrovesicular droplets of fat. 
Rats treated with Lutein $50 \mathrm{mg} / \mathrm{kg}$ showed only mild fatty degeneration of liver with only few microvesicular and macrovesicular droplets of fat (Figure 3).

Liver tissue of Atorvastatin treated rats at $5 \mathrm{mg} / \mathrm{kg}$ showed almost normal hepatocytes with only few microvesicular droplets of fat (Figure 4).

The tunica media of aortic tissue showed a large number of foam cells, necrotic core containing lipid debris, thrombi formation, neovascularisation and inflammatory cells (Figure 6).

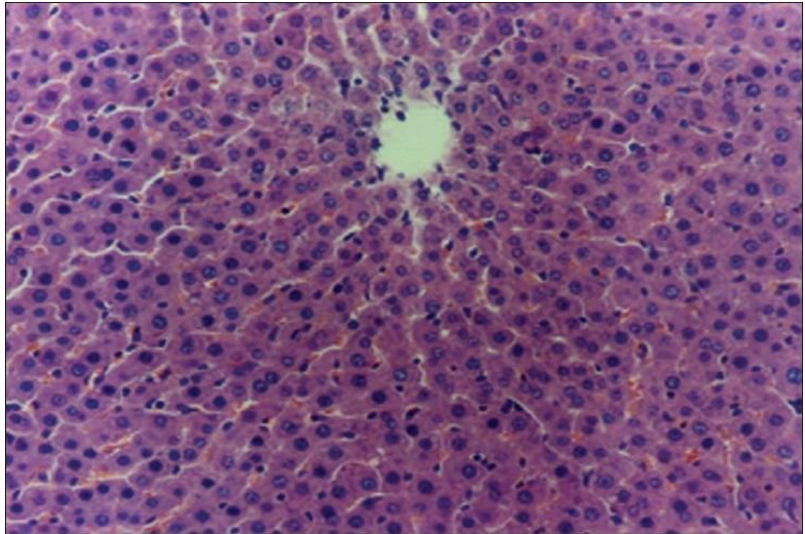

Figure 4: Liver tissue of high cholesterol diet fed rats treated with Atorvastatin $(5 \mathrm{mg} / \mathrm{kg})$ showing hepatocytes with few microvesicular droplets of fat.

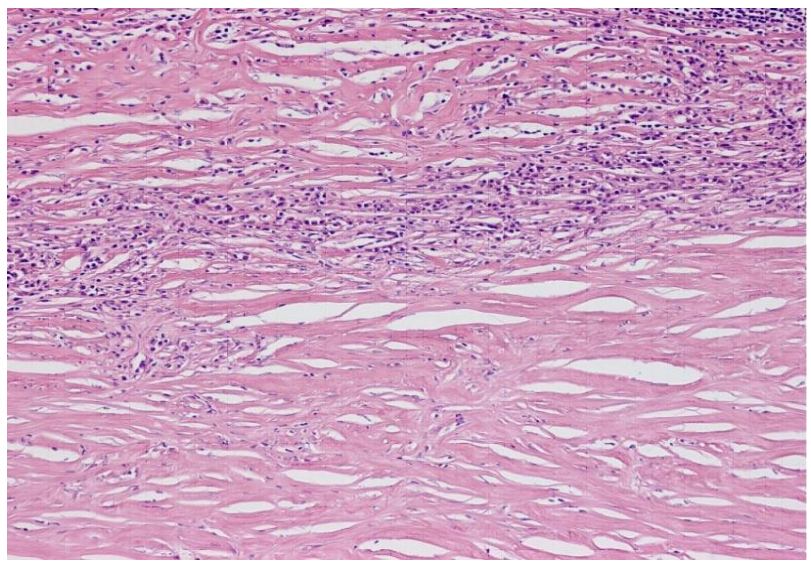

Figure 5: Aortic tissue of normal rat with few macrophage derived foam cells seen in the intima of aorta.

In Figure 6 the internal and external elastic membranes are attenuated, the media of artery is thinned and necrotic core containing lipid debris from dead cells, foam cells fibrin organized thrombi. Scattered inflammatory cells and neovasculirization are noticed.

Aortic tissue of rats treated with Lutein $50 \mathrm{mg} / \mathrm{kg}$ showed only intimal thickening with few foam cells and inflammatory cells (Figure 7). Atorvastatin $5 \mathrm{mg} / \mathrm{kg}$ treated rats showed only streaks of foam cells in the intimal wall of aorta (Figure 8).

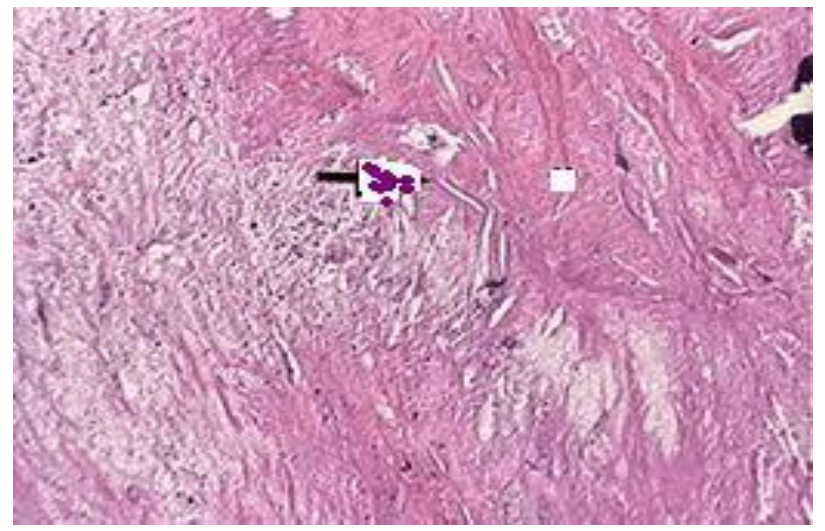

Figure 6: Aortic tissue of high cholesterol diet fed rat.

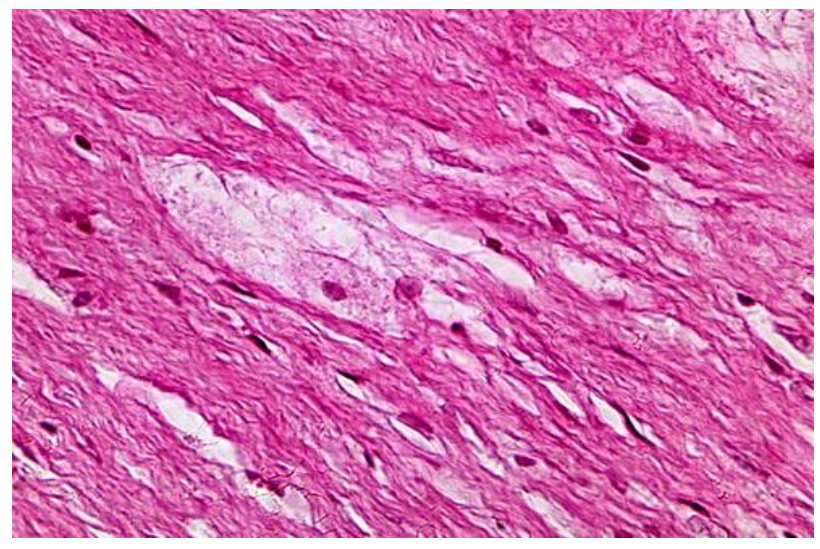

Figure 7: Aortic tissue of high cholesterol diet fed rats treated with Lutein $(50 \mathrm{mg} / \mathrm{kg})$. The wall of aorta shows intima thickening and lipid accumulation with few scattered inflammatory cells and foam cells.

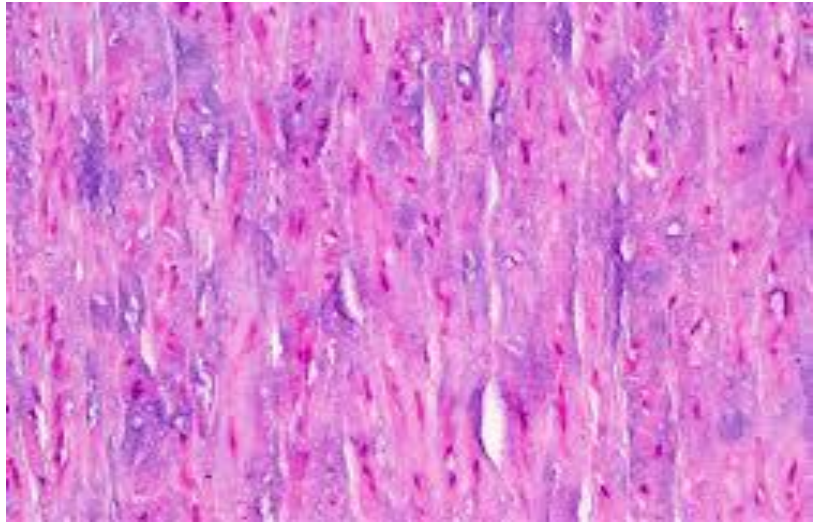

Figure 8: Aortic tissue of high cholesterol diet fed rats treated with Atorvastatin $(5 \mathrm{mg} / \mathrm{kg})$. The intimal wall of aorta shows streaks of foam cells.

\section{DISCUSSION}

Dyslipidemia including hypercholesterolemia and low levels of HDL_C are the major causes of atherosclerosis 
and atherosclerosis induced conditions, such as coronary heart disease (CHD), ischaemic cerebrovascular disease and peripheral vascular disease. Atherosclerosis remains the major cause of death and premature disability in developed societies. Number of human epidemiological studies and animal studies show that consumption of saturated fats, refined carbohydrates, as well as low consumption of vegetables and fruits tend to elevate the plasma cholesterol levels. Large epidemiological studies such as Framingham heart study confirmed the strong relationship between the elevated serum cholesterol and subsequent atherosclerosis and atherosclerotic related CHD. ${ }^{15}$

A great number of animal models, such as rabbits, mice, rats, chickens, swine, cats and dogs have been tested. ${ }^{16,17}$ The most commonly used method to evaluate antihyperlipidemic drugs and antiatherosclerotic drugs is "Cholesterol diet induced hyperlipidemia in rats". Rats fed on high cholesterol diet for thirty days show significant increase in serum and hepatic total cholesterol, LDL-C, VLDL-C, Triglyceride levels and decrease in HDL-C level. ${ }^{18,19}$

In the present study also male wistar rats were used for induction of hypercholesterolemia. At the end of 60 days it was observed that the rats fed on high cholesterol diet showed significant increase in serum total cholesterol, Triglycerides, LDL-C and VLDL-C. High cholesterol diet also reduced serum HDL-C. High cholesterol diet also significantly increased plasma total cholesterol, Triglycerides, LDL-C and VLDL-C. Rats treated with high cholesterol diet also showed reduced hepatic HDL-C. Treatment with Lutein significantly decreased serum total cholesterol, Triglycerides, LDL-C and VLDL-C. HDL-C was also increased significantly in Lutein treated rats.

Hyperlipidemia induces oxidative stress and the oxidative modification of lipoproteins in vessel wall might play a key role in atherogenesis. Hence in the present study also, to assess the oxidative stress associated with hyperlipidemia, lipid peroxides level in liver tissues were analyzed. Elevated levels of TBARS in tissue of high cholesterol diet fed rats was a clear manifestation of excessive formation of free radicals and activation of lipid peroxidation system by hyperlipidemia. Recent experimental and epidemiological evidence suggest that antioxidants like vitamin $\mathrm{C}$, vitamin $\mathrm{E}$, and $\mathrm{B}$-carotene, ubiquinone, bioflavonoids and selenium reduce LDL oxidation and reduce the risk of plaque progression and rupture. ${ }^{19,20}$ In the present study Lutein treated rats showed a marked reduction in TBARS. This result revealed the antioxidant property of Lutein.

The antioxidant role of Lutein in preventing the progression of atherosclerosis was studied by histopathological analyses of aortic and hepatic tissues of rats. Scientists have strongly proved that antioxidants control LDL oxidation in vivo and potentially slow atherosclerotic process..$^{20,21}$ In the present study also cholesterol diet fed rats showed increased fatty degeneration and foam cells in liver. The aortic tissue showed a large number of foam cells, necrotic core containing lipid debris and inflammatory cells. Lutein treated rat showed only a few microvesicular droplets of fat in hepatocytes at the higher dose. The intimal wall of aortic tissue showed only few streaks of foam cells.

\section{CONCLUSION}

Hence present study offers a conclusive evidence that Lutein is a hypolipidemic and antiatherogenic agent. Its good safety profile, easy availability and low cost are added advantages. Hence Lutein, as an antioxidant can be utilised in conjunction with other hypolipidemic medicines. Further studies are needed for the role of Lutein on cytokines like IL- 1 , TNF $\alpha$, Growth factors, PPAR $\alpha$ levels and others that contribute to atheromatous plaque evolution and its complications. This study will change the view upon antioxidants in general practice and a step ahead in taking a hand with natural products than allopathic medicine for treatment of hyperlipidemia.

\section{ACKNOWLEDGEMENTS}

Authors wish to thank their family members and their dear Professors, Department of Pharmacology and they are grateful to the technicians who supported them in the Department of Pharmacology, MGMCRI, Puducherry.

Funding: Funding sources from ICMR Sponsored STS Project approved and submitted in 2016

Conflict of interest: None declared

Ethical approval: The study was approved by the Institutional Animal Ethics Committee, MGMCRI, Puducherry (686/PO/Re/S/O2/CPCSEA)

\section{REFERENCES}

1. Thomas P. Bersot. Drug Therapy for Hypercholesterolemia and Dyslipidemia. In Goodman and Gilman's - The Pharmacological Basis of Therapeutics. Eds Laurence LB, Bruce AC, Bjorn CK, $12^{\text {th }}$ Edn. McGraw-Hill Book Co. Newyork; 2011:31:877.

2. Smith SC, Blair SN, Criqui MH, Fletcher GF, Fuster $\mathrm{V}$, Gersh BJ, et al. Preventing heart attack and death in patients with coronary disease. Journal of the American College of Cardiology. 1995 Jul;26(1).

3. Kannel WB, Schatzkin A. Sudden death: lessons from subsets in population studies. Journal of the American College of Cardiology. 1985 Jun;5(1):141B-9B.

4. Rajagopalan. A Review on the Ancient and Modern Views Regarding Medo Parinama Vikriti. Ancient science of life. 1989;9:1.

5. Mahley RW, Bersot TP. Drug therapy for hypercholesterolemia and dyslipidemia. Goodman \& Gilman's the pharmacological basis of therapeutics. $10^{\text {th }}$ Ed. New York: McGraw Hill; 2001:971-1002. 
6. Gate L, Paul J, Ba GN, Tew KD, Tapiero H. Oxidative stress induced in pathologies: the role of antioxidants. Biomedicine \& Pharmacotherapy. 1999 May 1;53(4):169-80.

7. Tomeo AC, Geller M, Watkins TR, Gapor A. Antioxidant effects of tocotrienols in patients with hyperlipidemia and carotid stenosis. Journal of lipids. 1995;30(12):1179-83.

8. Engler MM, Engler MB, Malloy MJ, Chiu EY, Schloetter MC, Paul SM, et al. Antioxidant vitamins C and $\mathrm{E}$ improve endothelial function in children with hyperlipidemia: Endothelial Assessment of Risk from Lipids in Youth (EARLY) Trial. Circulation. 2003 Sep 2;108(9):1059-63.

9. Qiu X, Gao DH, Xiang X, Xiong YF, Zhu TS, Liu LG, et al. Ameliorative effects of lutein on non-alcoholic fatty liver disease in rats. World Journal of Gastroenterology: WJG. 2015 Jul 14;21(26):8061.

10. Priyadharshini SK, Nirmala P, Kumar A. Effect of Lutein in Hypercholesterolemia induced Oxidative Stress in Male Wistar Rats. Int J Curr Pharm Res. 2015;7(2):97-100.

11. Parek AC, Jung DH. Cholesterol determination with Ferric acetate-Uranium acetate and Sulphuric acidFerrous Sulphate reagents. Anal Chem. 1970;42:4238.

12. Foster JB, Dunn RT. Stable reagents for determination of serum triglyceride by colorimetric condensation method. Clin Chim Acta. 1973;19:338-40.

13. Warnick GR, Albers JJ. A comprehensive evaluation of the heparin-manganese precipitation procedure for estimating high density lipoprotein cholesterol. Journal of Lipid Research. 1978 Jan 1;19(1):65-76.

14. Yagi K. Lipid peroxides and human disease. Chem Physiol Lip. 1978;45:337-57.
15. Moghadasian MH, Frohlich JJ, McManus BM. Advances in experimental dyslipidemia and atherosclerosis. Laboratory Investigation. 2001 Sep;81(9):1173.

16. Pramart NS, Shiv P. Antiatherosclerosis/AntiHyperlipedemic Activity. In Screening Methods in Pharmacology. Narosa Publishing House. India. 2006;14:297-304.

17. Vogel GH. Anti-Atherosclerotic activity. In Drug Discovery and Evaluation. $3^{\text {rd }}$ Edn. 2008;14:1661717.

18. Pandya N, Santani D, Jain S. Antioxidant activity of Ezetimibe in hypercholesterolemic rats. Indian $\mathrm{J}$ Pharmacol. 2006;38:205-6.

19. Araujo FB, Barbosa DS, Hsin CY. Evaluation of oxidative stress in patients with hyperlipidemia. PMID. 1995;117(1):61-71.

20. Stein JH, Keevil JG, Wiebe DA, Aeschlimann S, Folts JD. Purple grape juice improves endothelial function and reduces the susceptibility of LDL cholesterol to oxidation in patients with coronary artery disease. Circulation. 1999 Sep 7;100(10):1050-5.

21. Kita T, Nagano Y, Yokode M, Ishii K, Kume N, Ooshima A, et al. Probucol prevents the progression of atherosclerosis in Watanabe heritable hyperlipidemic rabbit, an animal model for familial hypercholesterolemia. Proceedings of the National Academy of Sciences. 1987 Aug 1;84(16):5928-31.

Cite this article as: Narayanamurthy U, Anandhi M, Manimekalai K. Effect of lutein on lipid profile in hypercholesterolemic rats. Int J Basic Clin Pharmacol 2018;7:859-65. 